\title{
An evaluation of kerbside recyclates collection as a means of enhancing waste recycling in Christchurch
}

\author{
C. Njue \\ School of Conservation Sciences, Bournemouth University, UK
}

\begin{abstract}
The fact that uncontrolled waste can lead to environmental and health risks has made it necessary to mitigate the degradation of water, soil and air. Several problems associated with traditional waste disposal methods such as lack of space for landfills and associated leachate, air pollution from incinerators and both the United Kingdom and European Union legislation on waste management has shifted attention to recycling as better option for waste disposal. The UK Government's Department of Environment, Transport and Rural Affairs (DEFRA) has given out guidelines on the latest performance indicator targets on recycling for individual local authorities. To enhance recycling and in order to meet the government's recycling targets, local authorities in the UK are currently using kerbside recycling programmes. To achieve the above targets, Christchurch Borough Council in the summer of 2003 introduced a new kerbside recycling scheme. Houses and businesses were provided with containers for separation of recyclable material. In June of 2003, a study was carried in Christchurch Borough, Dorset, England with the aim of evaluating kerbside recycling as a means of enhancing waste recycling. About 13,000 properties were surveyed. Findings from the research indicated a significant increase in the number of Christchurch residents participating in recycling. This increased participation was mainly attributed to the introduction of a new kerbside recycling scheme. Reasons were given for non-participation in the new kerbside recycling scheme. These form the basis of recommendations for an improved waste management framework. The substantial diversion of recyclables from landfills also proves why recycling and improved recycling schemes must play a major part in local, national and international waste management plans.

Keywords: kerbside recycling, waste recycling, performance indicator targets, evaluation, participation, improved waste management framework, mitigation, pollution, landfills, environment.
\end{abstract}




\section{Introduction}

About 371 million tonnes of waste are generated in the UK per annum [9] and about 8 million tonnes of it is Municipal solid waste [1]. This is about $0.9 \mathrm{~kg}$ of Municipal solid waste per person per day [3]. Waste generation in the UK increased by $2.7 \%$ between $1999-2000$ and $2000-2001$. It is estimated that at this rate, by the year 2020, the amount of waste generated will be twice the current and at the same time increasing the disposal costs to about $£ 1.6$ billion (Recycling and Waste World, 2003). About 50-60\% (by weight) of the household waste is recyclable material and yet the recycling rate for the same was only $5 \%-6 \%$ [6]. To protect the environment and public health, the UK Government set out a policy framework for sustainable waste management for the next 20 years. This policy framework was aimed at using material resources in a more efficient way with a view to reducing the bulk of generated wastes.

\subsection{Waste recycling}

Among the measures introduced in the policy framework were new statutory laws requiring waste collection authorities to formulate waste recycling plans [10]. Thus focus was shifted to waste recycling which comes third in the waste disposal hierarchy (i.e. reuse, waste exchange, recycling, composting and sanitary landfills). As at the year 1994, the average amount of household waste recycled nationally in UK was less than $5 \%$ with about $95 \%$ going to landfills. This contrasted with recycling figures of $15-20 \%$ in Europe and USA during the same period while in Japan, the high costs of landfill had encouraged recycling figures to $30 \%$ [9]. For local authorities, the set target by the year 2000 for waste recycling was $50 \%$ of the recyclates from domestic waste. The national recycling rates in UK were $11.2 \%$ and $13 \%$ by April 2001 and $2001 / 2$ respectively (DEFRA 2003, cited in [11]). The set target for local authorities by the year $2003 / 4$ was $22 \%$. However despite some promising results from some of the waste collecting authorities, it was not possible to achieve the national target of $25 \%$ recycling and composting. The reason for this was attributed to lack of financial resources, lack of government guidelines and failure to fully implement the European Union Directive. This target therefore had to be extended up 2005 (DETR 1999, cited in [10]). This resulted in local authorities revising their waste strategies with a view to meeting legislative targets. New kerbside recycling schemes were introduced to enhance recycling rates (Waite 1995, cited in [10]).

\subsection{Kerbside recycling}

Kerbside recycling is a means of providing households and businesses with a container suitable for separating of recyclable material. Householders are supposed to separate recyclates at source, keep them and put them by the kerbside to be collected [9]. In some schemes, the collection of green waste and uncooked food is included and may involve the provision of additional bins, plastic sacks or boxes [10]. The permitted recyclates for containers in various 
areas are different and also depend on the prevailing markets for recyclates. After collection, the recyclates are transported to a Materials Recycling Facility (MRF). Here they are sorted out and taken to the buyers [10]. In their research [10] reported that recyclates collected from this type of separation are uncontaminated. Among the items separated in this way and collected by for example compartmentalized collection lorries include: paper, glass, metals and plastics. The kerbside waste recycling is used to recycle most of solid waste in many countries [2]. Kerbside recycling is said to be liked by the public as opposed to the recycling centers. This is because some people do not have means by which to transport the recyclates to the recycling centers which otherwise goes to landfills. The response to kerbside recycling is said to be high and incorporating it with general waste collection would result in high tonnages of recycling [9]. It is suggested that environment is put into consideration and strike a balance by not using for instance double the energy in the collecting and delivering recyclates than what it will take to recycle it. At the same time it is necessary that a majority of the kerbside schemes will have to be molded in order to meet the local needs in addition to the available facilities and markets [9]. To enhance solid waste recycling, Kerbside solid waste recycling is now seen to be common phenomena in most of the local authorities in UK and the set recycling target may not be possible in the absence of the kerbside recycling [9]. Barriers to kerbside recycling include; inconvenience, Inadequate facilities and storage handling. However there is an increase of the number of residents who claim to recycle with the introduction of a kerbside waste recycling and therefore overcoming such problems (Barton and Perrin 2001).

\subsection{Kerbside waste recycling in Christchurch}

Christchurch is located in Dorset, England and covers about 50 square Kilometres. The location of Christchurch is shown in the map below. The population of Christchurch is about 44,869 (Census population 1981,1991 and 2000 , cited in [4]). The population density is about 891 people per square kilometre, the second highest in UK (Regional Trends ND, cited in [4]). As at the year 2002, about $87 \%$ of residents in Christchurch used recycling facilities (Christchurch Borough Council Panel Survey 2002, cited in [4]). This is an upward trend from

$70 \%$ in 1999 and 1996 (Residents Survey of 1996 and 1999, cited in [4]). Some of the common recyclates then were paper and glass. The high proportion of residents using recycling facilities at the time could have been attributed to the availability of recycling facilities in that about $84 \%$ of residents are reported to have access to recycling facilities (Christchurch Borough Council Panel Survey 2002 , cited in [4]). The other reason is the understanding by about $97 \%$ of residents of the need for recycling (Ibid ND, cited in [4]). In ranking order, some of the reasons for not recycling by residents as at the year 2002 were the unavailability of kerbside recycling, $(63 \%)$, the distance to recycle banks $(44 \%)$ and inability to get to the amenity sites (41\%) (Ibid ND, cited [4]). 


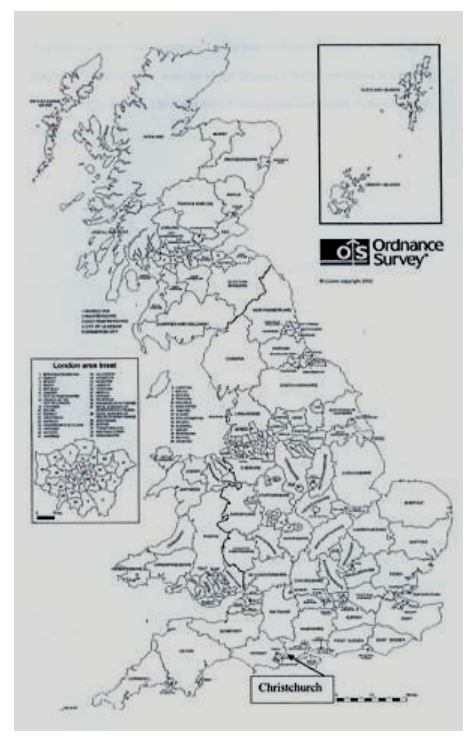

Figure 1: $\quad$ Map of the UK [7].

\section{Methodology}

To achieve the objectives of this study both primary and secondary sources of data were explored. The author accompanied the kerbside rounds lorry crew on their five-week rounds which covered 24 days. To obtain primary data, a survey was undertaken which involved field observation and use of questionnaires [9]. A list of property numbers for households who put out a green boxes or other containers for storing recyclates for example plastic bags by the kerbside in the target streets was recorded in a field note book. The number of individual properties whose residents participated on the scheduled recyclates collection dates were counted and recorded. Some flats were not included in this study as it would not have been possible to establish participating and non-participating households because the recycling facilities were communal.

The nature of the survey also warranted the use of self and verbally administered questionnaires. To establish reasons for non participation in the kerbside scheme, a survey of households not participating in the scheme was also simultaneously undertaken by door knocking and verbally administering the questionnaire to residents on reasons for not recycling. Reasons given for non participartion in the kerbside recycling scheme were noted. Data was also collected from secondary sources such as organisational documents, minutes of meetings, journals, association records and state statistical records. Care was taken as data from secondary sources for a study can be intended for a different primary reason [12]. 


\subsection{Sampling}

A sample survey of households was therefore undertaken in June and July 2003. Samples were drawn from a total of 527 streets and intended to cover 13,576 properties within five weeks. This is as depicted table 1.

Table 1: Recycling rounds and number of properties.

\begin{tabular}{|c|c|c|}
\hline $\begin{array}{l}\text { Recycling } \\
\text { rounds }\end{array}$ & $\begin{array}{l}\text { No. } \\
\text { stree }\end{array}$ & \begin{tabular}{l|l} 
& No.of \\
households \\
of \\
in the elect. \\
ets & roll \\
\end{tabular} \\
\hline Round A Week 1 & 121 & 2470 \\
\hline Round A Week 2 & 104 & 3093 \\
\hline Round B Week 1 & 94 & 2896 \\
\hline Round B Week 2 & 107 & 2678 \\
\hline Round C Week 1 & 129 & 2439 \\
\hline Totals & 527 & 13576 \\
\hline
\end{tabular}

Households in five different residential areas and on 527 different streets were selected for the study which took 24 days to complete. The sampled residential areas displayed similar characteristics. The samples were randomly selected and were therefore representative of the total properties in Christchurch. It was therefore considered that sampling about half the number of households out of a total number of 22,000 households who were issued with recycling boxes was expected to give a true representative on the rate of participation in the new kerbside recycling scheme.

\subsection{Scope and limitations of the study method}

It was difficult interviewing non-participating residents with hearing disability. In some cases there were more properties counted on the ground than those listed in the electoral roll while in some cases it was vice versa. Some houses were not numbered. The author either guessed the number from neighbouring houses and where this was not possible " +1 " was recorded under the names of respective streets. Changed collection schedule dates was another problem. For example it was not possible to collect data on $17^{\text {th }}$ July 2003 scheduled for Round C Week 1. This was because the collection dates had been rescheduled. At the time of the data collection, it was in summer and some residents had gone on holidays. Time and financial limitation was another limitation because the study was not fully funded and was to cover data collection for only five weeks and not six weeks as originally planned. 


\section{Results and discussion}

\subsection{Problems experienced during the launch of the new kerbside scheme}

A week prior to the launch of the kerbside scheme, recyclates boxes were delivered to households by a contracted company on behalf of the Council. Some of the problems encountered during this period were: mechanical problems with delivery vehicles, some properties received cards with the wrong collection dates and the lorry recyclates crew collection missed some green boxes and streets during their collection rounds. The overall impact of these problems adversely affected the overall tonnage of the recyclates collected during the first two weeks of the implementation of the scheme. This is as depicted in figure 2 and table 2.

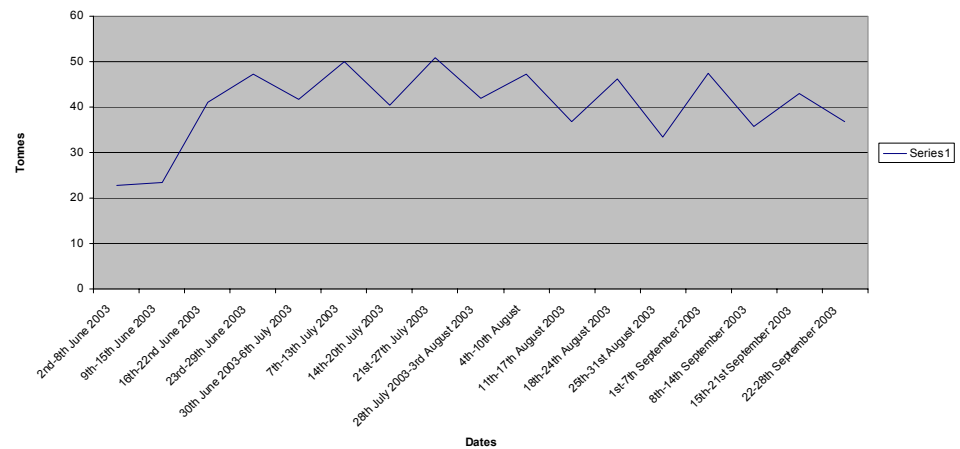

Figure 2: $\quad$ Recyclates tonnage [4].

An average of about 40 tonnes of recyclates was collected per week regime during the 17 weeks in the 4-month period (June to September 2003). During the first two weeks of scheme launch, only about 46 overall tonnes of recyclates were collected as opposed to an average of about 80 tonnes of recyclates which would otherwise have been collected [4].

\subsection{Level and participation percentage in the new kerbside scheme}

Data gathered from 527 streets over a five-week period covering 24 days is illustrated in table 2 .

Out of the total 12,974 properties surveyed, participants in the kerbside recycling scheme were about 8963 . Those households who did not put out the green boxes during the recycling rounds were about 4011. To get the participation $\%$ for the sample area the formula below was used.

$$
\text { Participation } \%=\frac{\mathrm{n}}{\mathrm{m}} \times 100
$$

$\mathrm{n}$ stands for number of households using the recycling box at least once in a 5 -week period and $\mathrm{m}$ for total number of households with recycling boxes in the same 5 -week period. This gives a recycling participation rate of $69.04 \%$. Table 2 also gives estimates on the total recyclates per week within the fortnight collection as well as the average weight of recyclates per household. It is worth noting that this percentage does not take into account flats in the 527 streets 
sampled who collectively shared recycling facilities. The reason for this was time and financial constraints which made it impossible to determine participants and non-participants in such cases as it would have meant interviewing individual households in these flats. This might also be the reason for the variance between the total properties recorded in the sampled area which were 12,974 and the total number of properties in the electoral roll which were listed as 13,576 . The difference was 602 properties and was $4.6 \%$ above the actual recorded properties in the study survey from the sample area. The pilot kerbside scheme carried out in 1989 covered about 3,200 properties. This fortnightly collection was for mixed paper, magazines, plastic bottles and cans. About 24 tonnes of recyclates were collected monthly with a participation rate of $52 \%$. In the new kerbside scheme, about 22,000 green boxes were given to households for glass bottles, mixed cans, newspaper and magazines. About 171 tonnes of recyclates are collected monthly and the participation rate is about $69.08 \%$. Some streets reported a $100 \%$ participation. This is a remarkable improvement taking into account that the collection of plastics is not included in the new kerbside scheme.

Table 2: $\quad$ Kerbside participation levels.

\begin{tabular}{l|l|l|l|l|l|l}
\hline & & Non & & \multicolumn{2}{|}{$\begin{array}{l}\text { Tonnes } \\
\%\end{array}$} & \\
Rounds & Part. & part. & Total \\
part. & recyc. & Kgs/property \\
\hline A Week 1 & 1642 & 718 & 2360 & 69.57 & 22.74 & 13.84 \\
A Week 2 & 1613 & 726 & 2339 & 68.96 & 23.31 & 14.45 \\
B Week 1 & 2128 & 915 & 3043 & 69.93 & 41.14 & 19.33 \\
B Week 2 & 2108 & 963 & 3071 & 68.64 & 47.34 & 22.45 \\
C Week 1 & 1472 & 689 & 2161 & 67.89 & 41.76 & 28.36 \\
Total & $\mathbf{8 9 6 3}$ & $\mathbf{4 0 1 1}$ & $\mathbf{1 2 9 7 4}$ & $\mathbf{6 9 . 0 8}$ & $\mathbf{1 7 6 . 2 9}$ & $\mathbf{1 9 . 6 6}$ \\
\hline
\end{tabular}

Source: Author's survey (2003)

\subsection{Reasons for non participation}

Some residents did not have boxes and newsletters. Other residents who were interviewed said that they are not willing to participate in the recycling project because they were not consulted. However these claims are reported not to be correct as the Council is said to have written in-house magazines that were distributed to every resident in Christchurch prior to the start of the kerbside scheme. Lack of space to store the green boxes in terms of space in the house and the house garages. This is common with households living in high-rise accommodation. This means that households with storage problems may not participate in kerbside recycling. Lack of adequate space to place recyclates boxes. Some residents were not using the recycle bins because sorting out recyclable materials and washing the tins is time consuming, cumbersome and inconveniencing. This was a response that came mostly from households having three or more young children and was therefore tied by the family cores. It is true that the Council requested residents (in the newsletters) to wash unbroken glass 
bottles and jars, food tins and drink cans. The reason for the cleaning was to make them clean for recycling. This is another barrier to waste recycling reported in the works of Vining and Ebreo (1990, cited in Tucker et al. 1998). Aylesford (1996, cited Turner, 1998) has indicated that recycling rates in households go below the nation average levels with the presence of young children. This is attributed to the fact that households are very busy when children are at young ages but as children become more enlightened, pressure is put on families to recycle. In a study, [2] reported that the average time taken by an American family is only 16 minutes a week to separate recyclable material. This translates to about 2 minutes a day. It would therefore be important to educate residents that recycling would not take much of their valuable time after all. The small size of the green box. Christchurch Borough Council has provided every household with a single green box. Any other extra box only available from the Council offices can be bought at a fee of $£ 2.00$. In several instances during the data collection on kerbside collection rounds, extra recyclable material was noticeable in plastic bags placed next to filled up green boxes. Some residents voiced concern that when it rains the recyclates in the paper bags get soaked. In practice, this means such recyclates might be rejected and therefore sent to landfills. This would defeat the intended purpose of recycling. It would be important for the Council to establish the percentage requiring extra boxes and if need be provide the same. Providing wheelie bins is another option the Council can try considering putting into account their viability as well as their acceptance by residents especially those lacking storage space. This would encourage more participation in the scheme. Disabilities. The green box is heavy especially when filled with such recyclates as bottles and residents with disabilities are therefore limited as to what can be put in. This forces some elderly residents to place their green boxes at the doorsteps of their houses and not by the kerbside. These boxes were not emptied because the recycling crew is limited to collect the boxes by the kerbside. However some disabled residents have improvised and have placed their green boxes on mobile trolleys. That disability was cited as one of the reasons for non-participation is an issue worth consideration. The demographic trend in Christchurch is skewed towards the elderly [4]. This is as depicted in figure 2.

If the council were able to identify the number and location of residents with disabilities (as a result of age, sickness or otherwise) and who are willing to participate in the kerbside scheme and hence consider providing such residents with wheel bins, then the participation rates would be rise. Forgetfulness of the collection dates. This was the case with a number of residents who had not put their boxes out for collection. However in some instances, it was clearly noticeable that some residents have stuck their kerbside collection date card schedules on top of their box lids.

Recylates collection schedules are attached to the communal containers for flats. This a good improvise as it clearly reminds them of the collection dates. However green boxes distributed to flats had the collection dates on cards stuck to them. The collection dates for the recyclates can also be posted on the Council's website. 


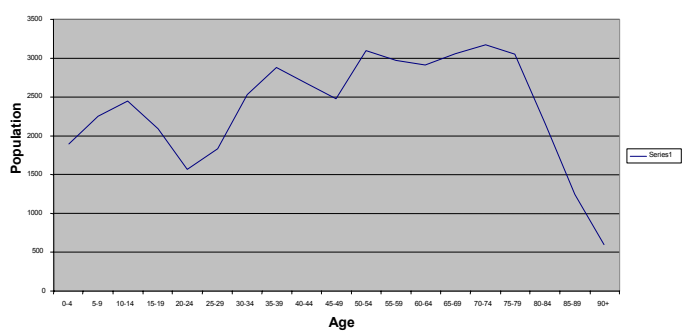

Figure 3: Population of Christchurch-2001. Adopted from the Census of Population (2001, cited in [4]).

\subsection{Environmental implications}

That recycling saves resources and energy is not in doubt. About 685 tonnes of recyclates from kerbside were diverted from landfills within four months of the inception of the new kerbside recycling scheme (June-September 2003). This was a saving on raw materials, energy, landfill space and subsequent reduction in Global warming which can also impact on climate change. However there was a possibility of some errors during the weighing of recyclates from the collection lorries such as the weighing of the lorry crew members during the weighing of recyclates collection lorries in one of the MRF. This can affect the actual recyclates tonnage.

\section{Conclusions and recommendations}

\subsection{Conclusions}

Overcoming some of the problems experienced during the launch of the project was crucial to the success of the new kerbside scheme. The effect of this was seen in the rise in recyclates collection from the third week of the new kerbside launch. That the public showed support for the new kerbside scheme is in no doubt as the high recycling rates in Christchurch suggest that residents have accepted the new kerbside recycling scheme. They are also conscious of the correct recyclates as the contamination for recyclates transported to Sita recycling facility is only about $4 \%$. That some additional boxes were being bought by residents from the council is even more encouraging. Christchurch Borough Council needs to focus its attention on reasons for non participation by some residents. Costs for the kerbside recycling programmes may be high and may not even be commensurate with financial returns at the moment but the long-term environmental benefits should be expected to be enormous. From the evaluation, a number of areas for improvements were identified. There was a significant shift from $52 \%$ kerbside recycling participation rate in the former kerbside scheme to about $70 \%$ participation rate in the new kerbside scheme. However despite this major improvement in the new kerbside participation rate, it still seems impossible for Christchurch Borough Council to achieve the government set targets. If the Council made improvements on critical areas, then there was the potential of achieving the $75 \%$ participation rate through the new 
kerbside recyclates scheme. This would further enhance the chances of Christchurch Borough Council nearing the government set targets of $22 \%$ by the end of 2003/04 financial year.

\subsection{Recommendations}

Among these are continuous consumer education, use of recycling symbols in packaging, inclusion of green waste in kerbside recycling, visits to best practices and further research on improvements to kerbside recycling.

\section{References}

[1] Biffa, (1997). The environmental Balance sheet, An analysis of Britain's waste production and disposal account, with implications for industry and government. The Beacon press, United Kingdom.

[2] Bulchholtz R. A. (1998). Principles of Environmental Management, The Greening of Business $2^{\text {nd }}$ Ed. New Jersey Prentice-Hall Inc, USA.

[3] Carra J.S. and Cossu R. (1990). International Perspectives on Municipal Solid Wastes and Sanitary Landfilling. Academic Press, Harcourt Brace Jovanovich, Publishers, London.

[4] Christchurch Borough Council (2003). The state of Christchurch; A profile of Christchurch and its residents, Christchurch Borough Council.

[5] Diaz L. F., Savage G. M., Eggerth. L. L. and Golueke C. G. (1993). Composting and Recycling. Lewis Publishers, Florida.

[6] McHarry J. (1993). Reuse, Repair, Recycle; Gaia books Limited, London.

[7] Ordinance Survey (2000). The map of United Kingdom, Ordinance Survey map. 'Reproduced with the permission of Ordinance Survey on behalf of The Controller of Her Majesty's Stationery Office (C) Crown Copyright' Licence No. ED 100018802 Bournemouth University, Talbot Campus, Poole, BH12 5BB.

[8] Pentecost A. (1999). Analysing Environmental data. , Addison Wesley Longman Singapore (Pte) Ltd Singapore.

[9] The Kindred Association (1994). A practical recycling handbook. Thomas Telford Services Ltd, London.

[10] Woodard R; Harder M. K; Bench M. and Philip M. (2001). Evaluating The Performance of a fortnightly collection of household waste separated into compastibles, recyclates and reuse in the south of England. Resources, Conservation and Recycling, Volume 31, Issue 3, Pages 265 284. Available from http://www.sciencedirect.com/science. [Accessed on $16^{\text {th }}$ September 2003]

[11] Faithful M. (2003). MRW material recycling week. Councils create extra capacity through MRF reconstruction, Vol.181 issue 20. Headly Brothers, Kent.

[12] Brunt P. (1997). Market research in travel and tourism. ButterworthHeinman, Oxford. 